\title{
Transanal Endoscopic Resection of a Rare Child Rectal PEComa Using Teo Platform: A Case Report and Review of Literature
}

\author{
Osama Eldamshety ${ }^{1 *}$, Nirmeen Megahed ${ }^{2}$, Ahmed Abdallah $^{1}$ and Essam Attia ${ }^{1}$ \\ ${ }^{1}$ Surgical Oncology Unit, faculty of medicine, Egypt \\ ${ }^{2}$ Pat1hology Department, Faculty of Medicine, Egypt
}

Received: 眥 January 09, 2019; Published: 瞤January 17, 2019

*Corresponding author: Osama Eldamshety, Lecturer of surgical oncology, Faculty of Medicine, Mansoura University, Geehan Street, Mansoura, 35516, Egypt

\begin{abstract}
A 9 years old female child presented a rectal mass with a well-defined margin, $3 \mathrm{~cm}$ in greatest diameter and $5 \mathrm{~cm}$ from the anal verge is reported. After full investigations, the tumor was excised guided by frozen section using TEO platform (Karl Storz, Tuttilingen, Germany). Diagnosis of perivascular epithelioid cell tumor (PEComa) is based on the co-existence of smooth muscle markers and melanocytic markers after immnohistochemical staining. After 1 year of follow up, there is no local or distant recurrence. PEComa has been described recently as a rare neoplasm of uncertain malignancy with no definite standardized management. A review of rectal PEComa in the literature was also described.
\end{abstract}

Keywords: PEComa; TEO; Transanal Surgery; Endoscopy; Rare Childhood Tumors

\section{Introduction}

Perivascular epithelioid cell tumour (PEComa), is a rare group of mesenchymal tumours consisting of perivascular epithelioid cells (PECs) with uncertain malignant potential that can occur in any part of the human body [1]. The cell type from which these tumours origin remains unknown. Normally, no perivascular epitheloid cells exist; the name refers to the characteristics of the tumour when examined under the microscope [2]. Perivascular epithelioid cell tumors (PEComa) are rare mesenchymal neoplasms and include angiomyolipoma, clear cell "sugar" tumor of the lung and extrapulmonary sites, lymphangioleiomyomatosis, and clear cell myomelanocytic tumor of the falciform ligament/ligamentum teres [3]. To our knowledge, few cases of PEComa were described in the uterus, kidney, liver, pancreas and bone. Only 5 case-reports of rectal PEComa in the literature were documented [4-7]. In addition, wider local excision of rectal PEComa using TEO platform (Karl Storz, Tuttilingen, Germany) was not previously described.

\section{Case Presentation}

A 9 years old female child presented with persistent constipation and rectal swelling. Colonoscopy examination revealed a swelling in the lower third of the rectum. The patient was investigated by pelvic MRI which revealed a well circumscribed rectal swelling, occupying the submucosa with invasion into the related mesorectum, no associated lymph nodes swelling and no invasion of the external anal sphincter or the levator anii muscle. CEA and CA19-9 biomarkers were normal. C.T. scan of the chest and the abdomen showed a normal scan. Examination under anaesthesia revealed a $3 \mathrm{~cm}$ sizable, right postro-lateral rectal swelling at $5 \mathrm{~cm}$ distance from the anal verge with intact overlying mucosa. Under general anaesthesia, the patient was put in lithotomy position and wider local excision of the tumor with its related mesorectum using TEO platform with a $4 \mathrm{~cm}$ size operating proctoscope diameter (Karl Storz, Tuttilingen, Germany) was done.

The procedure started by marking of the resection margins by electro-cauterization (Figure 1) and injection of methylene blue around the mass to help easy visualization of the planes around the mass (Figure 2). Continuation in the resection margins were guided by intraoperative histo-pathological frozen-section. Rectal repair by primary suturing with V-loc was done. Surgiflow was used to seal bleeding points and fill the cavity in the mesorectum behind 
the suture line. A Foley's catheter was used transanally as a drain for 2 days postoperatively. The Patient started full oral feeding in the 2 nd postoperative day and was discharged from hospital after 4 days. Using Kirwan scoring of the continence function, the patient was Kirwan grade one. Pathologic examination showed a well circumscribed tumoral proliferation formed of large clear cells with small vascular spaces in between (Figure 3). IHC revealed negative cytoplasmic staining to CD117 (Figure 4), positive staining for HMB-45 (Figure 5), SMA positive in vascular spaces with a negative cytoplasmic staining for SMA (Figure 6), inhibin, CK7, CK20, CD117, CD10, chromogranin, synaptophysin and CK.

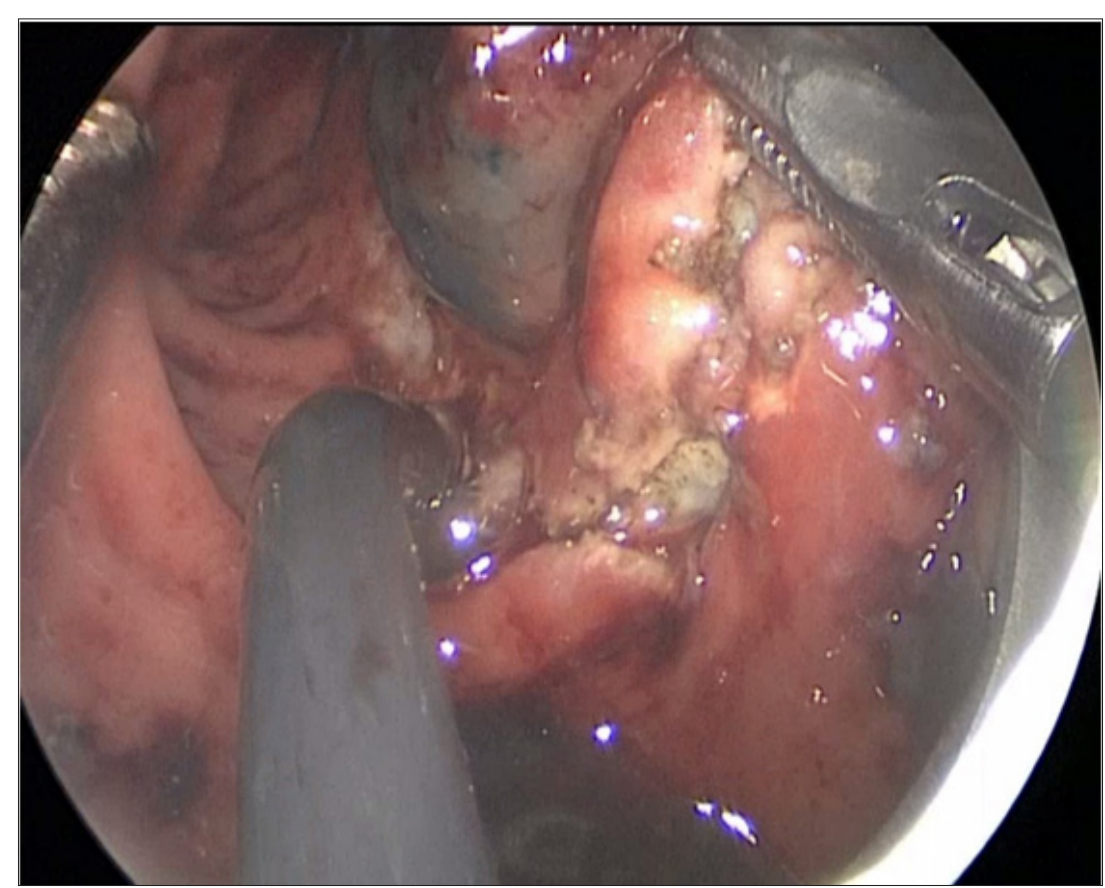

Figure 1: Transanal endoscopic injection of methylene blue into the tumor bed and determination of the excision margins by electrodiathermy.

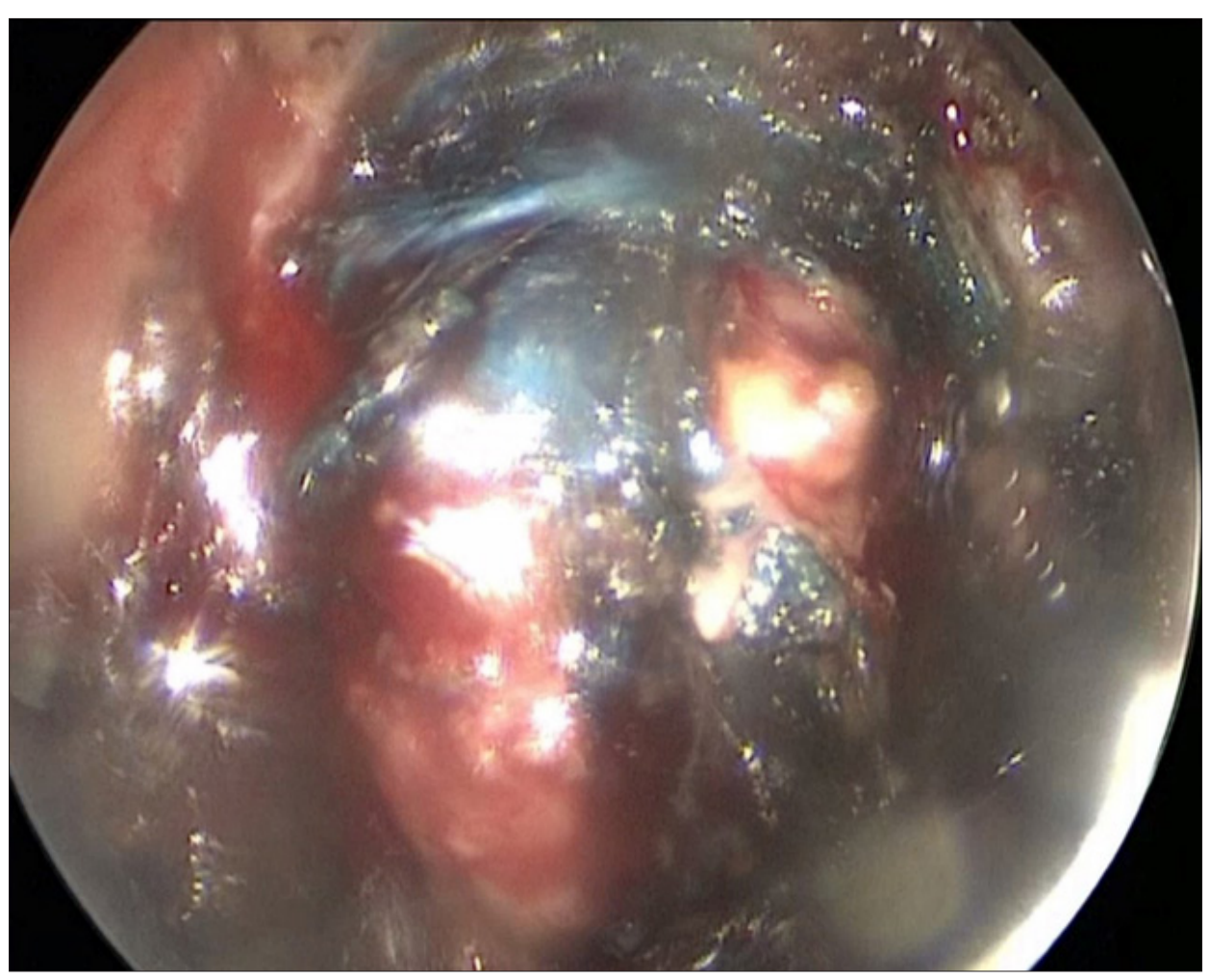

Figure 2: Injection of methylene blue around the mass. 


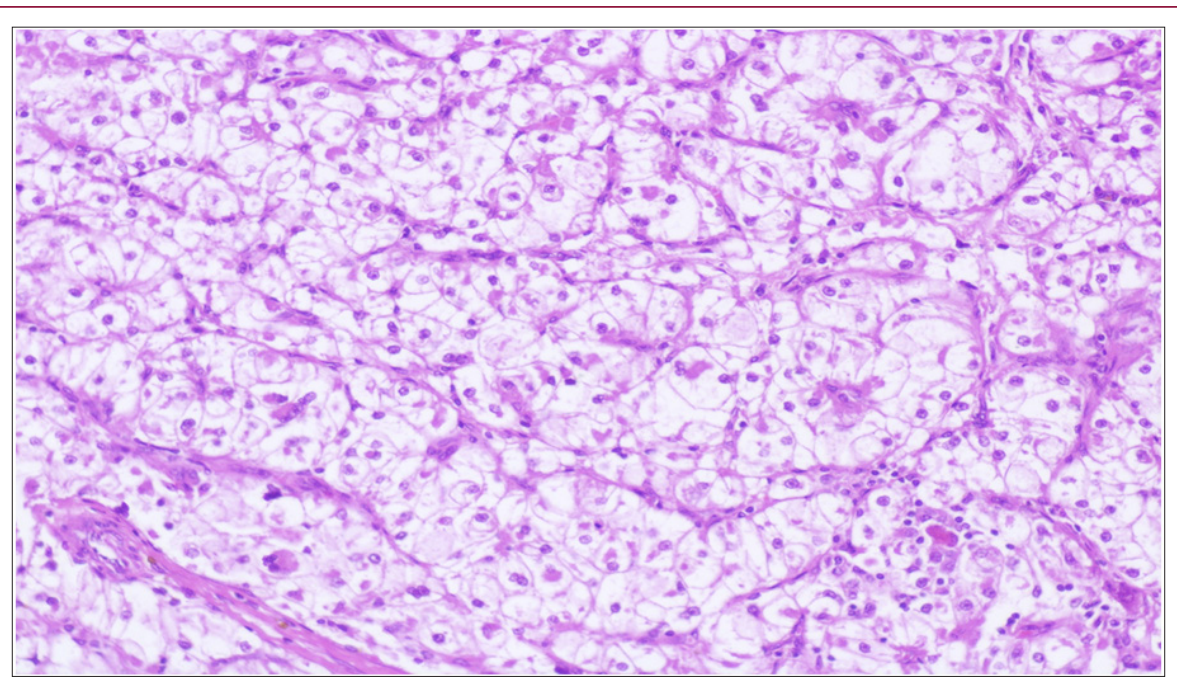

Figure 3: Perivascular tumor proliferation of large polygonal epitheliod cells exhibiting radial arrangement around lumen with clear to granular eosinophilic cytoplasm and small central round nuclei with small nucleoli (H\&E 200x).

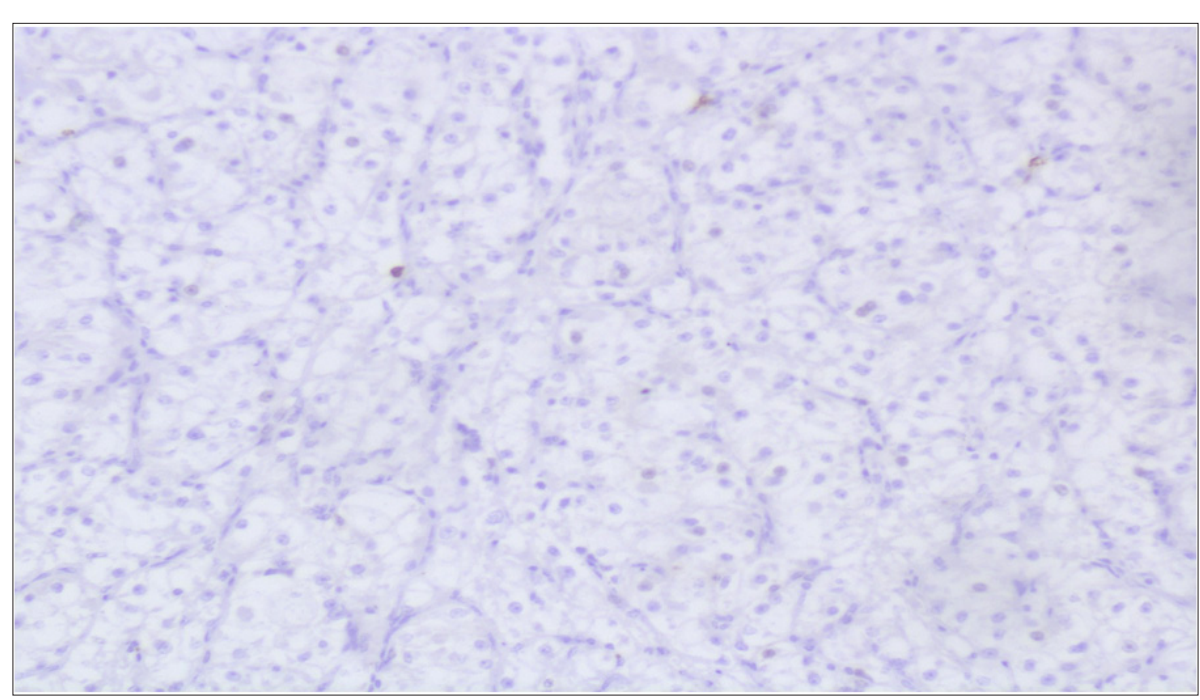

Figure 4: Tumor cells showed negative cytoplasmic staining to CD117 (200x).

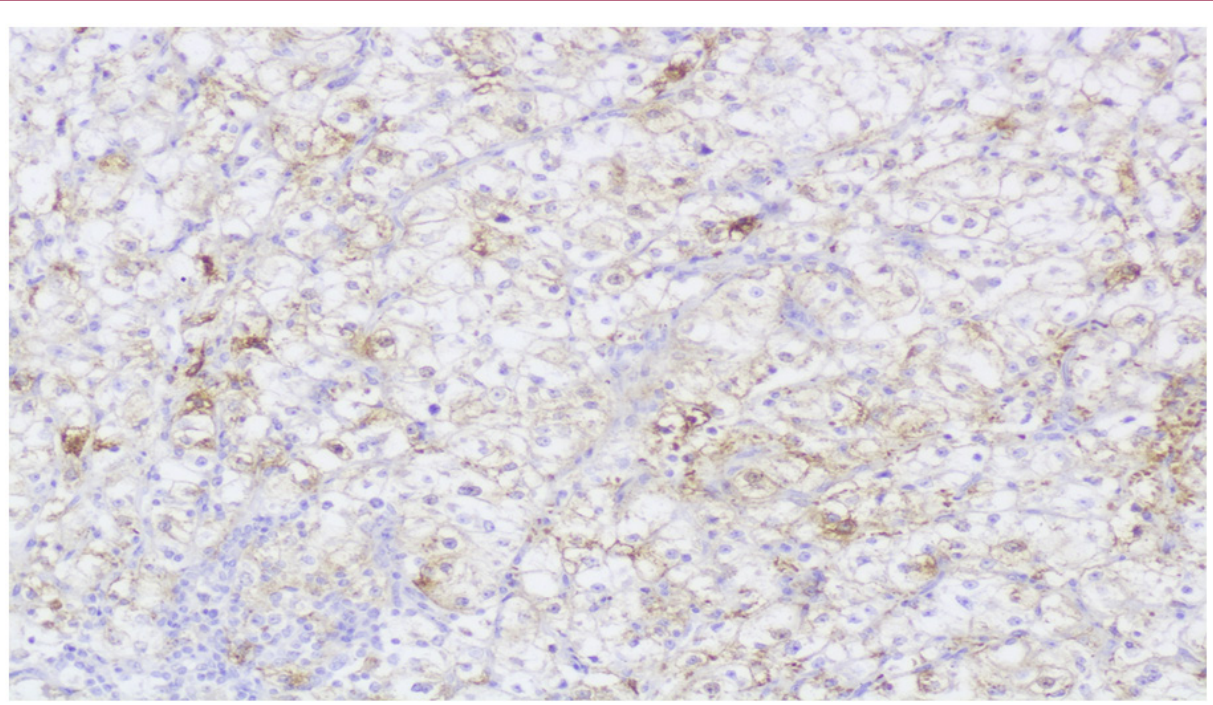

Figure 5: Tumor cells showed positive granular cytoplasmic staining for HMB45 (200x). 


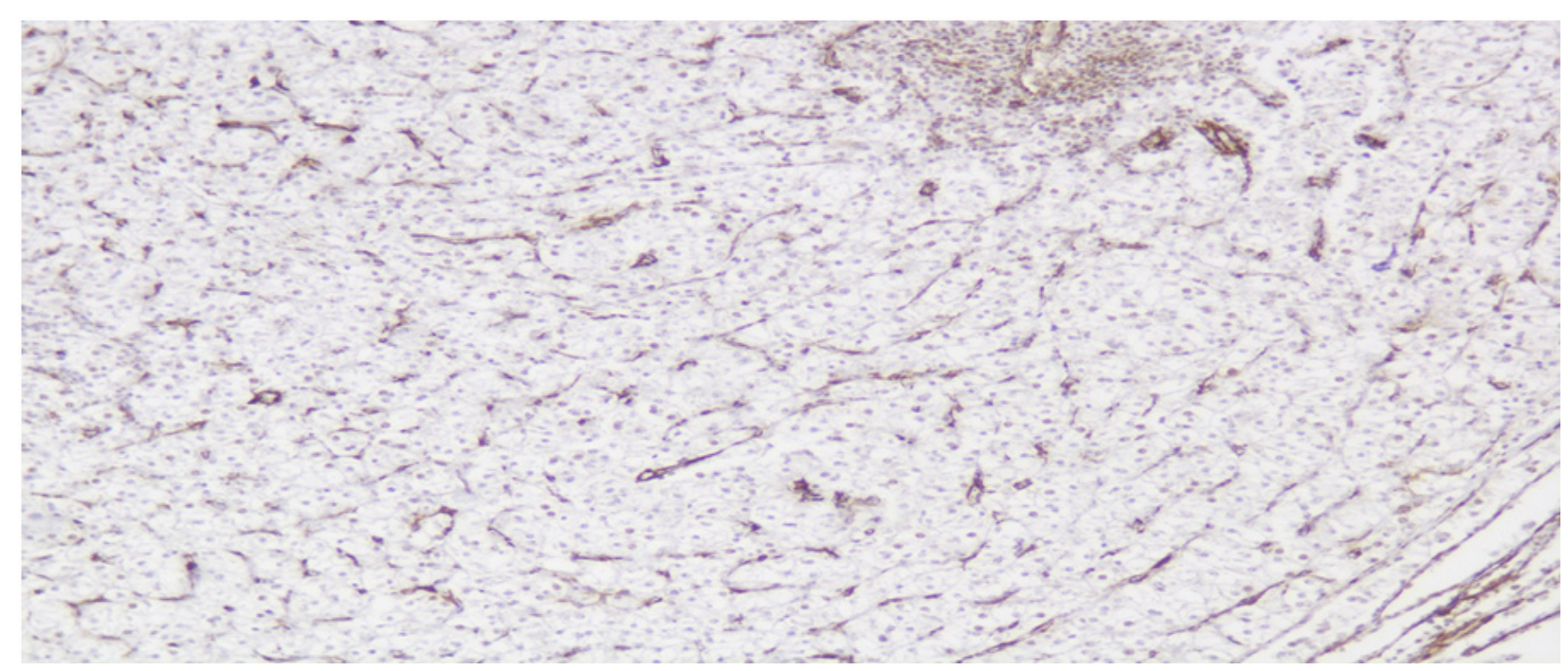

Figure 6: Tumor cells showed negative cytoplasmic staining for smooth muscle actin (200x).

\section{Discussion}

In 1992, PEComa was identified by the combined features of angiolipomas and clear cell "sugar" tumors of the lung [8]. In 2002, PEComa were recognized officially by the World Health Organization [9]. An Immunohistochemical staining for PEComa is the main tool for diagnosis of the coexistence of positivity for smooth muscle and melanocytic markers [10]. In our case, epithelioid type of gastrointestinal stromal tumor (GIST) was the main differential diagnosis. Exclusion of GIST was based on immunohistochemical ground with CD117, CD34 showing negative results and positive HMB-45. The decision to do a radical resection with total mesorectal excision or local excision in the recent case was controversial because rectal PEComa is a very rare neoplasm with no either definite standardized management or distinctive criteria for the malignant potentiality. Radical resection of the sigmoid and rectum with adjuvant chemotherapy was previously used for treatment of rectal PEComa with lymph nodes metastases [11]. Local excision using transanal endoscopic microsurgery was an alternative [7]. Based on being a small tumor involving 1/3 of the rectal circumference with no regional lymph node metastases, wider local excision was suggested as a proper choice. Recently, transanal endoscopic surgery is the best approach for wider local excision due to the capability to achieve a free safety margin with unblock resection of the very low located rectal tumor with its associated mesorectum. More Practically, the transanal wider local Excision of a very low rectal tumor of unknown malignancy behaviour in a child is a challenging procedure because of the absence of a small diameter operating TEO proctoscope. Using Kirwan grading [12], the patient was continent to gas, fluid and solid stool (grade one). The postoperative continence function was not affected by the use of the adult TEO platform. The long-term treatment outcome of PEComa remains vague due to limited evidence from case reports.
2. Folpe AL and Kwiatkowski DJ (2010) Perivascular epitheloid cell neoplasms: pathology and pathogenesis. Human Pathology 41(1): 1-15.

3. Argani P, Aulmann S, Illei PB, Netto GJ, Ro J, et al. (2010) A distinctive subset of PEComas harbors TFE3 gene fusions. Am J Surg Pathol 34(10): 1395-1406.

4. Tazelaar HD, Batts KP, Srigley JR (2001) Primary extrapulmonary sugar tumor (PEST): a report of four cases. Mod Pathol 14(6): 615-622.

5. Evert M, Wardelmann E, Nestler G, Schulz HU, Roessner A, et al. (2005) Abdominopelvic perivascular epithelioid cell sarcoma (malignant PEComa) mimicking gastrointestinal stromal tumour of the rectum. Histopathology 46(1): 115-117.

6. Ryan P, Nguyen VH, Gholoum S, Carpineta L, Abish S, et al. (2009) Polypoid PEComa in the rectum of a 15-year-old girl: case report and review of PEComa in the gastrointestinal tract. Am J Surg Pathol 33(3): 475-482.

7. Kanazawa A, Fujii S, Godai T, Ishibe A, Oshima T, et al. (2014) Perivascular epithelioid cell tumor of the rectum: report of a case and review of the literature. World Journal of Surgical Oncology 12: 12.

8. Bonetti F, Pea M, Martignoni G, Zamboni G (1992) PEC and sugar. Am J Surg Pathol 16(3): 307-308.

9. Folpe AL (2002) Neoplasms with perivascular epithelioid cell differentiation (PEComas) In: Fletcher CDM, Unni KK, Mertens F, editors. World Health Organization classification of tumors. Pathology and genetics of tumors of soft tissue and bone. Lyon: IARC Press, pp. 221222 .

10. Panahova S, Rempp H, Sipos B, Malek NP, Boozari B (2015) Primary perivascular epitheloid cell tumour (PEComa) of the liver - is a new entity of the liver tumors? Z Gastroenterol 53(5): 399-408.

11. Ryan P, Nguyen VH, Gholoum S, Carpineta L, Abish S, et al. (2009) Polypoid PEComa in the rectum of a 15-year-old girl: case report and review of PEComa in the gastrointestinal tract. Am J Surg Pathol 33(3): 475-482.

12. Kirwan WO, Turnbull RB Jr, Fazio VW, Weakley FL (1978) Pullthrough operation with delayed anastomosis for rectal cancer. Br J Surg 65(10): 695-698.

\section{References}

1. Martignoni G, Pea M, Reghellin D, Zamboni G, Bonetti F (2008) PEComas: the past, the present and the future. Virchows Arch 452(2): 119-132. 


\section{ISSN: 2574-1241}

DOI: $10.26717 / B J S T R .2019 .13 .002366$

Osama Eldamshety. Biomed J Sci \& Tech Res

(c) (i) This work is licensed under Creative

Submission Link: https://biomedres.us/submit-manuscript.php

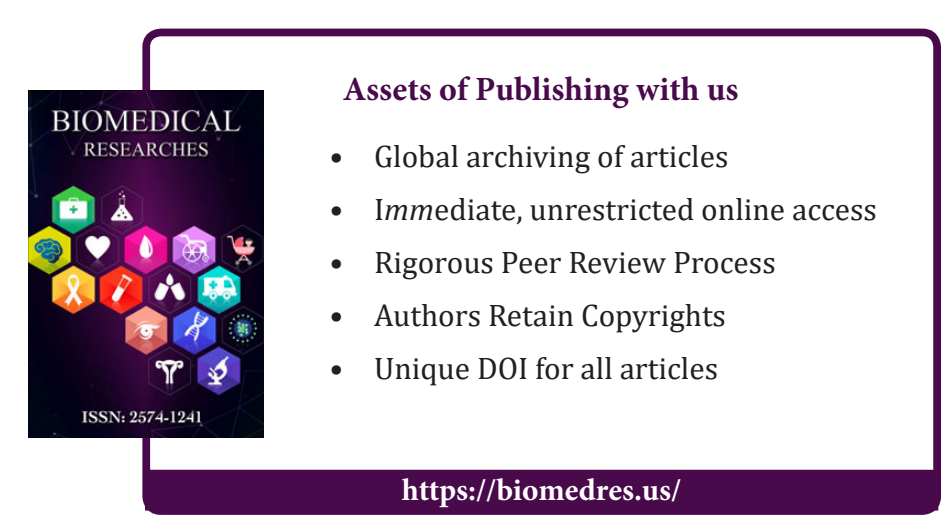

